\title{
P 088 WHAT IS THE QUALITY OF END OF LIFE CARE FOR THOSE WHO DIE AT HOME? A STUDY TO EXPLORE THE VIEWS AND EXPERIENCES OF BEREAVED CARERS'
}

Carolyn Lees, ${ }^{1}$ Catriona Mayland, ${ }^{2}$ Angela West, ${ }^{3}$ Alison Germaine ${ }^{4} .{ }^{1}$ Liverpool Community NHS Trust, Liverpool, UK; ${ }^{2}$ Aintree University NHS Trust; ${ }^{3}$ Liverpool John Moore's University; ${ }^{4}$ Liverpool Institute of Palliative Medicine

10.1136/bmjspcare-2014-000654.129

Background The quality of end of life care has been the focus of much government policy. Collecting data from those who are dying is complex (Mitchell, 2002) but it appears that relatives and carers' views provide a valuable evaluation of the patient's end of life care, synergised with their own unique experiences as carers (Mayland et al, 2012).

Aim To explore bereaved carers' experiences of end of life care for those who had died at home using a validated tool.

Methods A mixed method approach comprised of a self completed questionnaire allowing respondents to provide narrative to support their responses. Two hundred and ninety one patients who had an expected death at home were identified. Narrative data from the questionnaires were analysed using framework analysis identifying prominent words and phrases, expanded to include associated key words or themes (Richie \& Spencer, 1994).

Results Four main themes and associated sub themes emerged from the narrative data. The main themes were coordination and continuity of care, competence, compassion and communication. Quantitative data will not be presented here.

Discussion The findings from this study reflect that generally good quality care was provided for those who died at home. There were examples of well orchestrated care with services working well together, but there were times when adequate support was not evident.

Conclusions With the number of deaths globally set to increase there is a need to identify tools which measure the quality of end of life care for those who choose to die at home in order to improve the experiences of patients and carers. The CODE questionnaire represents a user friendly, comprehensive tool to achieve this.

\section{REFERENCES}

1 Mayland C.R., Williams E.M.I., Ellershaw J.E. (2012) Assessing quality of care for the dying: the development and initial validation of a postal self-completion questionnaire for bereaved relatives. Mayland C.R., Williams E.M.I., Ellershaw J.E. Palliative Medicine 26(7):897-907.

2 Mitchell G.K. (2002) How Well do General Practitioners Deliver Palliative Care? A Systematic Review, Palliative Medicine, 16; 457-64.

3 Richie J., Spencer L. (1994) Qualitative Data Analysis for Applied Policy Research, (Bryman and Burgess, eds) Analysing Qualitative Data London. 